\title{
O DIÁlOGO DA TRADIÇÃO E DA RENOVAÇÃO - SOBRE A MONTAGEM DE TRISTÃO E ISOLDA DE RICHARD WAGNER POR PETER KONWITSCHNY
}

\author{
Alexandre Sobreira Martins*
}

\begin{abstract}
Resumo: A presente comunicação busca fazer uma leitura da montagem de Peter Konwitschny do drama musical Tristan und Isolde, do compositor alemão Richard Wagner encenada no Teatro Nacional de Munique durante o Festival de Ópera de Munique de 1998, considerando-o como uma revisão pós-moderna que busca romper com a tradição de encenações wagnerianas, trazendo o conteúdo do drama de Wagner para nosso contexto atual; essa leitura será feita à luz das propostas de Christopher Innes e Artaud sobre a representação teatral e as leituras de Homi Bhabha e Michel Foucault sobre a pós-modernidade.
\end{abstract}

Palavras-chave: Richard Wagner, Tristão e Isolda, pós-modernidade, história, drama, ópera, Foucault, Bhabha, Innes, Artaud.

O drama musical Tristão e Isolda, de Richard Wagner, é uma obra que sustenta seu conteúdo sobre o pilar de um duplo e denso caráter psicológico e filosófico. Embora possa ser considerada, à primeira vista, uma tragédia (já que seus dois protagonistas morrem ao final), ela não o é necessariamente. Sob a leitura de Wagner, a proposta de Schopenhauer da libertação do mundo através da negação da vontade transforma-se na libertação das amarras sociais e limitações morais do mundo para que os heróis do drama possam experimentar a plenitude total da unificação através do amor no reino/ventre-materno da morte/noite. O drama cria para nós uma oposição entre o mundo do dia, que representaria as convenções rígidas de uma ordem social artificial - a "vontade" (Wille) que Schopenhauer desejava negar - e o mundo da noite, o "[...] reino maravilhoso do qual nos afastamos sempre mais quando procuramos entrar nele com a mais veemente força" ${ }^{1}$, onde, através do amor, poderíamos nos unir, negando a individualidade e, assim, experimentando a plenitude absoluta da união amorosa.

Tudo isso, é claro, não é nada verdadeiramente schopenhaueriano. Mas a leitura que Wagner faz dele é a de um ultra-romântico já na segunda metade do século XIX, que, ainda por cima, era dotado de uma grande vitalidade e forte energia sexual, como o pode demonstrar mesmo um exame superficial de sua biografia. A obra já foi lida de várias maneiras, embora a análise de conteúdo geral que apresentei acima seja, basicamente,

\footnotetext{
* Professor Titular da Faculdade Pitágoras - BH/MG. UFMG.

Mestre em Estudos Literários pela Faculdade de Letras da Universidade Federal de Minas Gerais -

$1 \quad[\ldots]$ wondrous realm from which we stray the furthest when we strive to enter it by fiercest force. Wagner "Prelude to Tristan und Isolde. In GOLDMAN, s/d, p. 273.
} 
aceita pela grande maioria dos críticos ${ }^{2}$. Em termos de montagem, este drama, concentrado em questões de natureza psicológica e filosófica, com pouquíssima ação exterior, não é exatamente o tipo de peça que convida a cenários extravagantes. Em 1971, Günther Schneider-Siemssen projetou e August Everding dirigiu, uma montagem do drama no Metropolitan de Nova York, em que todo o cenário do segundo ato, a chamada sequiência do Liebesnacht (Noite de Amor), constitui-se de um palco totalmente escurecido, em que apenas os bustos e rostos dos dois cantores/atores podem ser vistos iluminados, tendo acima deles uma constelação de luzes simulando estrelas, como se fossem duas borboletas (antigo símbolo para a alma) ${ }^{3}$. Outra montagem, também projetada por Schneider-Siemssen para o Festival da Páscoa de Salzburg, também prima pela simplicidade do cenário: o primeiro ato, o navio de Tristão que leva Isolda da Irlanda para a Cornualha, é representando apenas por duas imensas velas, enquanto que o palácio de Tristão em Kareol, no terceiro ato, é apenas uma paisagem rochosa quase plana, em que se destaca um plano inclinado no proscênio, à direita, que faz as vezes do leito em que Tristão jaz, ferido e delirante, durante todo o ato, tendo ao fundo apenas uma imensa tela representando, a um só tempo, o céu e o mar. Todo o resto é tratado apenas por jogos de iluminação.

Em uma proposta bastante diversa dessas, temos uma produção relativamente recente, com a montagem dirigida por Peter Konwitschny, encenada no Teatro Nacional de Munique durante o Festival de Ópera de Munique de 1998. Segundo o comentário da contracapa do DVD,

O TRISTÃO E ISOLDA de Peter Konwitschny se mostra uma interpretação refrescantemente controversa deste grande clássico. Em suas mãos, a gigantesca opera de Wagner se torna uma obra otimista sobre duas pessoas que conseguem encontrar o amor. É um enfoque estimulante a esta ópera eternamente fascinante. ${ }^{4}$

Para uma melhor compreensão de minha proposta, um breve sumário do enredo se faz necessário. Deixarei de lado, aqui, quaisquer considerações musicais, pois a orquestra em Wagner atua como um personagem, como mais uma voz, no sentido da função que Bakhtin atribui aos romances plurivocais, ou como o coro das tragédias gregas, no sentido clássico de comentarista ou suplementar à ação dramática, como o próprio Wagner nos informa $^{5}$. O enredo em si é simples: Tristão vai à Irlanda para buscar Isolda para que se case com seu tio, o Rei Marke. A princesa irlandesa mostra-se furiosa e desdenhosa para com o herói inglês que, em contraste, é honrado e louvado por todos. A razão disso é clara: os dois estão perdidamente apaixonados, mas são incapazes de confessar seu amor, Isolda por orgulho, Tristão por respeito ao código da cavalaria, que impediria que alguém de sua posição (um mero cavaleiro e órfão, ainda por cima) desposasse uma mulher de sangue real. Isolda decide matar Tristão com uma bebida envenenada e acompanhá-lo na morte.

\footnotetext{
$2 \quad$ CF. MILLINGTON, 1995.

Cf. CIRLOT, 1998, p. 35 e CHEVALIER, 1991, 138-9.

Peter Konwitschny's TRISTAN UND ISOLDE proves to be refreshingly controversial in its interpretation of this grand classic. In his hands, the towering Wager opera becomes an optimistic work about two people who succeed in finding love. It is an exciting approach to this endlessly fascinating opera.

5 WAGNER, "Orchestra's power of speech; analogy with gesture". In GOLDMAN, s/d, pp. 217-219.
} 
Tudo isso ouvimos enquanto ela faz confidências à sua dama de companhia, Brangäne, a quem agora ordena que prepare a "bebida da morte". A pobre Brangäne, dividida entre amor e obediência a sua senhora, opta por preparar o chamado "filtro do amor". Atendendo ao chamado peremptório de Isolda, Tristão vem à sua presença, os dois trocam alguns golpes verbais que escondem/revelam seus sentimentos mútuos e, acreditando ambos estarem tomando veneno, sorvem a poção de amor. Imediatamente, se vêm livres das amarras de orgulho e códigos sociais que os impediam e, arrebatadamente declaram seu amor mútuo, exatamente quando o navio de Tristão está aportando na Cornualha e seu tio, o Rei Marke, está vindo a bordo para receber a noiva prometida.

O segundo ato é um longo monólogo em que Tristão e Isolda discorrem sobre a natureza "schopenhaueriana" de seu amor, a busca da libertação das limitações físicas e sociais do mundo terreno, associado com o dia, em direção à plenitude de união amorosa no mundo da morte, associado com a noite. São, enfim, surpreendidos pelo Rei Marke. Melot, um amigo de Tristão, também está apaixonado por Isolda e, por isso, traiu Tristão. Marke lamenta amargamente o que considera como a traição do sobrinho pelo qual fizera tanto, Tristão lhe diz que o que há entre ele e Isolda está além de sua compreensão e, fingindo desafiar Melot para um duelo, deixa que este lhe inflija uma ferida moral.

No terceiro ato, Tristão se encontra em seu castelo em Kareol, quase moribundo. Praticamente todo este ato é tomado por um longo delírio de Tristão, em que somos levados a compreender sua psicologia interior e o conflito tremendo entre lealdade ao código da cavalaria e amor por Isolda. Esse conflito o leva à morte, exatamente no momento em que Isolda chega para reencontrá-lo. O Rei Marke chega logo em seguida e, depois de uma batalha inútil em que o servo de Tristão, Kurwenal, mata Melot e é morto pelos guardas do Rei, diz que veio dar seu perdão e sua bênção aos amantes após descobrir que não houvera qualquer relação carnal entre eles. Mas já é tarde: em meio a uma visão extática, em que vê Tristão, as feições luminosas, pairando no céu cercado de estrelas, Isolda morre, acompanhando assim seu amado até o "ventre da noite eterna", mergulhando em "do hálito do universo / o alento unificante".

Como se encaixa nisso o trabalho de Konwitschny? Não pretendemos, aqui, verificar o sucesso ou fracasso de sua tentativa. Eugenio Barba considerava que o teatro europeu estava congelado na rigidez e complacência de sua própria imutabilidade conservadora e propunha, sob a influência de Artaud e Grotowsky, um teatro revolucionário, capaz de efetivamente integrar-se com seu público em uma comunhão mútua de investigação da própria condição humana. Não temos espaço aqui para verificar se Konwitschny consegue (ou sequer tenta) alguma coisa nesse sentido ou se sua proposta de renovação do clássico wagneriano é bem-sucedida.

Primeiramente, vejamos os signos que ele nos oferece em sua proposta. No primeiro ato, trata-se não do navio do herói Tristão, mas de um navio de cruzeiro, do qual Tristão é o capitão. Isolda e Brangäne nos são mostradas em alegres e leves vestidos em um estilo bastante correspondente ao estereótipo do turista europeu. Brangäne fica, inclusive, durante um bom tempo, brincando com um copo de alguma bebida colorida trazida a ela por um camareiro de bordo vestido com trajes bastante caricaturais de um garçom de bordo dr cruzeiros de luxo (o qual, incidentalmente, é quem canta a famosa "canção da moça irlandesa" e que, segundo as instruções de Wagner, não deveria aparecer em cena, mas deveria entoar seu canto do alto do mastro principal do navio. Como não se trata mais de um navio medieval à vela, mas de um moderno barco de cruzeiro, ele aparece em cena cumprindo a função de camareiro). Já de imediato se estabelece um tremendo contraste 
entre a dramaticidade intensa e violenta da música e do texto e a colorida e alegre montagem que temos diante dos olhos. Para completar esse contraste, quando Tristão surge em cena, ele está se barbeando, tendo um uniforme de capitão sobre o qual, incongruentemente, encontra-se em seu peito uma espécie de couraça de armadura, em cima da qual foi colocada a típica toalha de barbeiro. Ele está absorto em contemplar-se num espelho (Konwitschny traça seu retrato do personagem aparentemente inspirado por uma observação azeda de Isolda, que o chama de "Eigenholder", literalmente, "aquele que dá demasiada atenção a si mesmo"). Quando Tristão vai ver Isolda ele, comicamente, ainda está com a toalha de barbeiro e com uma das faces cobertas de espuma de barbear. Mas, ao mesmo tempo, todos os elementos fixos do cenário, desde o mastro do navio até as cordas com bandeirolas, são brancos e distorcidos, de aparência intensamente expressionista, como que a nos remeter para o domínio puramente espiritual e psicológico da ação. Da mesma maneira, o monólogo final da "Morte de Amor" de Isolda, é feito "fora do palco": as cortinas se fecham, isolando os demais personagens da ação, e ficam em cena apenas Tristão e Isolda, completamente de preto, contemplando-se mutuamente enquanto Isolda canta sua despedida do mundo das aparências e sua união com Tristão no reino da morte.

O material de Wagner é mítico em sua natureza. E, como bem nos demonstra Christopher Innes ${ }^{6}$, o trabalho mítico e ritualista tem sido uma das principais vertentes do teatro de vanguarda contemporâneo. Mas como trazer esse mito medieval ao agora, como presentação, como diz Artaud? A mera reconstituição de encenações históricas não e capaz de fazê-lo, pois está relacionada à memória enquanto passado, não enquanto vivência atual recriada, literalmente viva. Nessa montagem, encontramo-nos diante de duas representações diferentes, que tendem a convergir no infinito em um duplo ato que fica expresso nos dois níveis de presentação colocados diante de nós. Em um deles, o nível do poema musical Wagneriano, vemos a tragédia dos amantes separados pelas convenções sociais, que encontram a felicidade na união transcendental da morte. No outro, vemos o casal de amantes, pessoas comuns, que encontram a felicidade pela rejeição das convenções sociais e, ao mesmo tempo, pela libertação do vínculo com o ato de ficção do texto wagneriano. Mas isso se dá não pelo retalhamento ou transformação desse texto, mas pela manipulação do espaço espetacular e da maneira como os atores investem as personagens nesse espaço e se comportam dentro dele. De um cenário que mescla elementos oníricos e realistas em convivência paradoxal, saímos, por assim dizer, fora da peça quando os dois cantores/atores saem do cenário. As cortinas se fecham atrás deles e são deixados sós para que Isolda cante seu monólogo final em que vê Tristão em toda sua beleza e esplendor, os olhos cintilantes de amor, acolhendo-a na união por que ambos tanto ansiavam.

É vital para se aceitar essa proposta que nos lembremos que Isolda, nesse momento, está contemplando Tristão como se ele estivesse vivo. Isso permite ao diretor dar um salto semiótico da estrutura ficcional do palco (que nos preparou para isso através da apresentação ambígua e multi-crônica, ao invés de anacrônica) para o real, o fora do palco, esse gesto mesmo uma metáfora da transcendência que Wagner nos propõe em seu texto. Daí a fragmentação e mescla de elementos aparentemente anacrônicos, que fundem o mito com o cotidiano, mostrando sua presença viva no espírito humano.

Esses elementos, por sua vez, que rompem com a proposta transcendental do drama, nos oferecem um quadro que aponta para uma leitura que carrega em si os elementos de rompimento e fragmentação que caracterizam a cultura atual. Contrário ao que propõe

$6 \quad$ INNES, s/d. 
Bhabha, no entanto, e falando claramente de seu local de enunciação, Konwitschny nos mostra uma montagem que, ainda assim, busca romper com a tradição wagneriana européia. Temos a clara impressão de que é um europeu falando para europeus através de imagens da cultura e história da Europa. Mas a mistura de estilos (vestuário moderno, navio de cruzeiro moderno, mas com cenário expressionista e com marinheiros de aparência quase medieval em uma espécie de cabine decorada com lanças e escudos de papier maché branco, a couraça no peito de Tristão, as vestes cerimoniais do Rei Marke, bordadas a ouro), tudo isso aponta para uma estrutura pós-moderna em que elementos históricos e presentes se mesclam, recusando-se a assumir tanto o que Homi Bhaba chama de "signo mimético da contemporaneidade histórica [ou] o marco final visível do passo histórico" 7 , mas sim um local de intermediação em que as fronteiras desses passados e de suas revisões pelo presente se entrecruzam, criando dessa forma uma leitura que consegue compartilhar dialogicamente tanto da tradição quanto de sua revificação em um mundo que, por seus elementos oníricos e anacrônicos entre si, parece ainda mais real, pois nos oferece signos da diversidade e multiplicidade cultural de nosso próprio tempo.

Como coloca Foucault, a história do saber é sempre re-interpretada pelas mudanças do presente, procurando sempre estabelecer séries de relações que não podem ser reduzidas a um esquema linear. ${ }^{8}$ Assim, Konwitschny tenta nos mostrar uma leitura que, misturando elementos anacrônicos e de realidade e sonho, consciente e inconsciente, apresentaria uma estrutura performática que se abre à multiplicidade do presente sem rejeitar os elementos históricos que formaram a tradição do drama que procura, agora, renovar. Ao contrário: ele procura estabelecer um diálogo constante entre seus vários enunciados, entre o passado e o presente. 


\title{
Referências Bibliográficas
}

BHABHA, Homi. O Local da Cultura. Trad.: Myriam Ávila... [et al.]. Belo Horizonte, Editora da UFMG, 1998.

CHEVALIER, Jean e GHEERBRANT, Alain. Dicionário de Símbolos. Coord.: Carlos Sussekind. Trad. Vera da Costa e Silva... [et al.]. 4a. ed. Rio de Janeiro, José Olympio, 1991.

CIRLOT, J. E. A Dictionary of Symbols. Trad. Jack Sage. Londres, Routledge, 1988.

CULSHAW, John. Wagner the man and his music. Metropolitan Opera Guild Composer Series. Londres, Hutchinson \& Co., 1979.

FOUCAULT, Michel. A Arqueologia do Saber. Trad.: Luiz Felipe Baeta Neves. $7^{\text {a }}$. Ed. Rio de Janeiro, Forense Universitária, 2004.

GOLDMAN, Albert e SPRINCHOR, Evert [eds.]. Wagner on Music and Drama: a compendium of Richard Wagner's prose works. Trad. H. Ashton Ellis. New York, Da Capo Press, s/d.

INNES, Christopher. El Teatro Sagrado: El ritual y la vanguardia. México, Fondo de Cultura Económica, s/d.

MILLINGTON, Barry (org.). Wagner, um compêndio: guia complete da música e da vida de Richard Wagner. Trad.: Luiz Paulo Sampaio e Eduardo Francisco Alves. Rio de Janeiro, Jorge Zahar Editor, 1995.

WAGNER, Richard. Tristan und Isolde (vídeo). Produção de Bayerischer Rundfunk/RM Associates. Diretor de Palco: Peter Konwitschny. Direção para a Televisão e Vídeo: Brian Large. Chatsworth, Estados Unidos da América, 1999. 2 DVDs, 241 min. color.

\begin{abstract}
This paper aims at an interpretation of the staging by Peter Konwitschny of German composer Richard Wagner's music drama Tristan und Isolde at the Munich National Teatre during the 1998 Munich Opera Festival, taking it as a post-modern revision, which attempts to break with Wagnerian staging tradition by bringing the contents of Wagner's drama into our contemporary context; this analysis will be made by approaching the ideas of Christopher Innes and Artaud on staging and of Homi Bhabha and Michel Foucault on post-modernity.
\end{abstract}

Keywords: Richard Wagner, Tristand und Isolde, post-modernity, history, drama, opera, Foucault, Bhabha, Innes, Artaud. 